\title{
La dinámica productiva como límite superior de los salarios en la industria argentina
}

\author{
Facundo Barrera Insua, ${ }^{*}$ Mariana Fernández Massi**
}

Perfiles Latinoamericanos, 25(50)

2017 | pp. 301-329

DOI: $10.18504 / \mathrm{pl} 2550-014-2017$

\begin{abstract}
Resumen
El objetivo de esta investigación es contribuir al debate en torno a los determinantes del salario. Este artículo centra su análisis en los diferenciales interindustriales en la relación entre productividad y salarios en la Argentina del periodo 2003-2012. Mediante un análisis cuantitativo se distinguen las pautas de evolución de tal relación. Se concluye que durante el primer quinquenio (2003-2007) ha habido un incremento del salario real mayor al de la productividad para todos los sectores industriales; mientras que en el quinquenio siguiente el comportamiento ha sido más heterogéneo. Así, la reducción de la desigualdad salarial no ha estado explicada por una reducción similar de la desigualdad productiva.
\end{abstract}

\begin{abstract}
The aim of this research is to contribute to the debate on the factors that determine workers' wages. This paper focuses its analysis on the inter-industry differentials in the relationship between productivity and wages in Argentina during 2003-2012. Based on quantitative analysis we distinguish patterns of evolution of that relationship. We conclude that there has been an increase of real wages greater than that of productivity for all industrial sectors during the first five years (2003-2007); while in the next five years the performance has been mixed. Thus, the reduction in wage inequality has not been explained by a similar reduction in the productive inequality.
\end{abstract}

Palabras clave: productividad, salarios, heterogeneidad, industria, Argentina, índice de Theil. Keywords: Productivity, wages, heterogeneity, industry, Argentina, Theil index.

* Doctor en Ciencias Sociales, por la Universidad de Buenos Aires. Miembro del Centro de Estudios e Investigaciones Laborales (CEIL-CONICET) y de la Universidad Nacional Arturo Jauretche | fbarrera@ceil-conicet.gov.ar

** Magíster en Ciencias Sociales del Trabajo por la Universidad de Buenos Aires. Miembro del Centro de Estudios e Investigaciones Laborales (CEIL-CONICET) y de la Universidad Nacional de Moreno | mafebahia@gmail.com 


\section{Introducción ${ }^{1}$}

\section{A}

partir de comienzos del siglo xxI, se dio un proceso de "inflexión distributiva” en América Latina y el Caribe: entre los años 2002 y 2011 se observa que quince de los diecisiete países de la región muestran mejoras distributivas.

Dichas mejoras han sido objeto de debate. En algún caso, se ha sostenido que el factor originario de la desigualdad era la productividad diferencial de los ocupados en distintos estratos productivos (Infante, 2011). En otro, se señala como argumento central que se reduce la brecha salarial entre trabajadores calificados y de baja calificación (López-Calva \& Lustig, 2010). Incluso se ha destacado el crecimiento de la masa salarial — producto del incremento de los niveles de empleo-, lo que afecta favorablemente las condiciones en las que se vende fuerza de trabajo (Pérez \& Barrera, 2012). Sin embargo, más allá de los enfoques utilizados, se posiciona al mercado de trabajo en el centro de la explicación. Aquí se retoma la preocupación por los determinantes de los ingresos dentro del mercado laboral. En particular, nos interesa analizar el vínculo entre productividad y salarios, a través de un análisis sectorial.

La relación entre productividad y salarios se ha estudiado desde distintas ópticas. La teoría neoclásica parte de la premisa que sostiene que, de no mediar rigideces externas, el salario iguala la productividad marginal. Bajo el enfoque propuesto en este artículo, la productividad también es uno de los principales determinantes del salario, pero a partir de su medida promedio y no marginal. La lógica subyacente es distinta. En el enfoque estándar, la productividad es un atributo del individuo que depende de características personales. Así, la productividad la determinan los años de escolarización y entrenamiento en el trabajo: trabajadores más productivos recibirán salarios superiores. En cambio, desde una lectura marxiana, la productividad se vincula al puesto de trabajo y la determinan fundamentalmente las condiciones productivas del establecimiento/firma. De allí que, para comprender los niveles de salario, resulte primordial comprender las condiciones de acumulación de los sectores económicos que pagan esos salarios.

En el modelo teórico adoptado aquí, la tasa salarial efectiva puede aumentar en tanto no cuestione la tasa de ganancia del capital a nivel sectorial, lo que prefigura un límite superior al incremento de los salarios. Dentro de ese límite, la productividad toma un papel significativo ya que impacta de manera directa en las tasas de ganancia sectoriales.

1 Agradecemos especialmente los comentarios de la Dra. Adriana Marshall, y de los evaluadores anónimos del artículo. Los errores u omisiones que aún pudieran existir en el texto son de exclusiva responsabilidad de los autores. 
Con el objetivo de contribuir al conocimiento del proceso de cambio de la tendencia de la desigualdad en la región, este artículo se enfoca en el análisis de los diferenciales interindustriales en la evolución de la productividad y los salarios para el caso de la Argentina entre los años 2003 y 2012. En este país, la salida de la crisis económica de 2001 inicia una etapa en la que los salarios en el sector industrial muestran una notable expansión. La industria contiene buena parte del sector privado registrado, a priori "ganador" en lo que se refiere a la recomposición de los ingresos de los trabajadores, sin embargo, esta tendencia no ha sido homogénea en las distintas ramas de actividad del sector.

El artículo se organiza en cinco secciones, de las cuales esta introducción es la primera. En la segunda se desarrollan la perspectiva teórica sobre la determinación del salario adoptada aquí y los aspectos metodológicos más relevantes. Luego, en la tercera, se presentan algunos elementos que caracterizan el periodo en estudio. Con el propósito de analizar el acercamiento/alejamiento del salario efectivo de su límite superior, en la cuarta sección se exponen los resultados empíricos sobre la relación entre salarios y productividad en la industria manufacturera. Finalmente, se presentan las principales conclusiones del artículo y los nuevos interrogantes surgidos a la luz del mismo.

\section{Marco de análisis}

El problema de la desigualdad salarial ha sido debatido extensamente en la literatura económica tomando como punto de partida la concepción general acerca del funcionamiento del mercado de trabajo y los mecanismos de determinación del salario. En este apartado planteamos, en primer lugar, cuáles son los elementos clave en la determinación de salarios y, en segundo, cómo se plasma empíricamente el enfoque adoptado.

Sobre la relación entre la productividad y el salario

En la actualidad, las lecturas más frecuentes provienen de la escuela neoclásica, misma que retoma la explicación de las fuerzas del mercado y traslada la definición del salario a la esfera de la circulación, desanclando su vínculo con la órbita productiva. En la teoría de salario de equilibrio, el funcionamiento del mercado de trabajo es el mismo que para cualquier otra mercancía, la oferta y la demanda se encargarán de fijar el precio y el nivel de ocupación. En este modelo, la productividad aparece como una propiedad del trabajador e interesa en relación a sus aportes marginales: en los supuestos de competencia 
perfecta, sin mediar rigideces externas, una empresa maximiza sus ganancias al pagar un salario real que iguale la productividad marginal del trabajo, lo que significa que se pagará en función del incremento del producto generado por la incorporación de un nuevo trabajador. En el equilibrio, el salario tendrá un doble significado: visto desde la demanda será el pago por el producto adicional creado por el trabajo, y visto desde la oferta, será el ingreso marginal que obtiene la última hora de trabajo ofrecida (Carciofi, 1986).

$\mathrm{Al}$ ser entendida como un atributo individual, la productividad se encuentra directamente relacionada con los ańos de formación de los trabajadores. Los salarios serán proporcionales a sus productividades personales, debidamente ajustados según el stock de capital humano: a mayor educación, mayor será su productividad y, en consecuencia, sus ingresos serán más altos (Mincer, 1974). La forma más divulgada de estimar el retorno a la educación es mediante una función econométrica de segundo orden, según la cual, la variación de los ingresos laborales se explica por el promedio de años de educación y la experiencia laboral. ${ }^{2}$ En este marco, Mincer (1974) explica las diferencias salariales al señalar su vínculo con los distintos niveles de formación de los trabajadores.

Por otra parte, íntimamente relacionado con la productividad, el progreso técnico aparece en los modelos de crecimiento como una variable exógena. Este es el caso del conocido desarrollo de Solow (1956), donde el término que representa el cambio tecnológico afecta la posición de la función de producción y no su pendiente. Luego, en los modelos de crecimiento endógeno, el progreso tecnológico pasa a depender de variables como la acumulación de capital físico, humano y tecnológico, por lo que afecta la tasa de crecimiento futuro.

Un último punto que se debe destacar sobre este tipo de modelos tiene que ver con que la productividad se construye a partir del aporte del trabajo y del capital, factores que son complementarios en la función productiva. Así entendida, la productividad no solo descansa en los aportes aislados de los respectivos factores, sino que se invisibiliza el conflicto de intereses entre empresarios y trabajadores organizados.

Una lectura alternativa proviene de la teoría marxiana, donde la productividad debe ser analizada en relación con la competencia por el mercado. Mediante la entrada y salida de capitales en las distintas esferas de la producción, se establece un ratio oferta-demanda donde se definirá un beneficio medio para el conjunto de los mercados. Allí, el ritmo de acumulación de la economía, junto con sus ramificaciones sectoriales, aparece como la variable independiente

2 La tasa de retorno de la educación está dada por el coeficiente de la variable educación y se interpreta como el porcentaje en que se incrementan los ingresos por cada unidad (ańo) adicional de educación, manteniendo todo lo demás constante. 
crítica: tendencialmente ajusta para que la oferta y demanda del mercado de trabajo mantengan la tasa de salarios dentro de los niveles "normales" de beneficio (Botwinick, 1993). Es decir, en casos excepcionales, un ritmo de acumulación acelerado presiona sobre la oferta de trabajo, reduce la masa de trabajadores desocupados, incrementa los salarios y comprime la tasa de beneficios. Si esto sucede, se ralentizará el ritmo de acumulación hasta que se establezca una apropiada relación entre oferta y demanda (Marx, 2004 [1867]).

De manera teórica, es posible pensar que las tasas salariales pueden variar al interior de ciertos límites que garantizan el "normal" funcionamiento de la economía. De ser así, puede pensarse un límite superior dado por la tasa de ganancia, y uno inferior influido por las condiciones materiales necesarias para la reproducción del trabajador y su familia (Botwinick, 1993; Marshall, 1979; Watson, 2002).

En lo que se refiere al límite superior, tal como se explicitó arriba, este se relaciona directamente con la tasa de ganancia. Esta es un promedio de los resultados de la pulsión por adquirir una porción de mercado y suplantar a sus competidores en el conjunto de la economía. A su vez, la utilización de diversos métodos de producción de diferentes edades, en cualquier industria dada, establece un abanico de tasas de ganancias que se recrea permanentemente con la dinámica de la acumulación de capital (Shaikh, 1980).

En caso de que la tasa de ganancia caiga por debajo de su nivel "normal" como producto del incremento de salarios, su recomposición se dará en la esfera de la circulación a través del sistema de precios. Es decir, en un sistema de fijación de precios y salarios, los primeros funcionan como "la variable independiente" (Marshall, 1979). Esto se deriva de la asimétrica distribución del poder entre empresarios y trabajadores, presente en las condiciones de producción y distribución de la economía capitalista. Una vez establecida la tasa de ganancia mínima aceptada, el límite superior puede ser aproximado a partir del estudio del ritmo de crecimiento de la productividad del trabajo y los precios (Marshall, 1979).

La productividad, entendida como un atributo del puesto de trabajo y determinada esencialmente por las condiciones productivas del establecimiento/firma, juega un papel central dentro de la competencia capitalista. Aquellos capitales que tengan los métodos de producción más eficientes, tendrán una estructura de costos inferior, principal herramienta para el enfrentamiento con otros capitales (Shaikh, 1980). Un aumento de la productividad es al mismo tiempo una reducción en el costo medio de producción no explicado por cambios en los costos relativos de los factores de la producción. A mayor productividad, mayor reducción de costos y mayor posibilidad de incremento de los salarios, dados los precios en los productos vendidos tanto en el mercado interno como en el externo. 
De esta forma, según la mirada propuesta en este artículo, el disímil desarrollo del cambio tecnológico, extensión de la jornada y/o intensidad productiva de la fuerza de trabajo, se encuentran en el centro de la explicación de una estructura salarial desigual. Aquellos sectores económicos con un mayor crecimiento de la productividad media desplazarán el límite superior logrando mejores beneficios, en caso de que el salario medio no acompañe ese ritmo de crecimiento. En el caso inverso, en aquellos sectores en los que el ritmo medio de los salarios crece por encima de la productividad, la restricción estará cada vez más cerca de hacerse efectiva, lo que podría afectar las condiciones de acumulación del capital sectorial. Por último, en caso de que las variables mencionadas crezcan a igual ritmo, la distribución de salarios y ganancias se mantendrá constante, al igual que el límite que estas fundan.

Luego, cuán cerca o lejos de ese techo se fije el salario efectivo, dependerá de la fortaleza que posean para impulsar el conflicto los colectivos de trabajadores (Botwinick, 1993) y de la política pública destinada a la regulación del salario, la que puede favorecer o menoscabar el accionar de los trabajadores.

\section{Medidas de productividad y salarios}

En la sección precedente señalamos que las fuentes básicas del crecimiento de la productividad son la incorporación de tecnología y las mejoras en la organización productiva. Intentar medir estas mejoras de la productividad conlleva diferentes problemas metodológicos y conceptuales que brevemente desarrollamos aquí.

Una de las formas principales de incrementar el producto por trabajador es extender su jornada de trabajo. Si se analiza el producto por trabajador, este incremento en la cantidad de horas trabajadas redundará en aumentos de productividad. En los estudios sobre la Argentina, diversos autores utilizan indicadores de productividad por trabajador (Beccaria \& Yoguel, 1988; Graña \& Kennedy, 2008), mientras que otros, para aislar este factor, recurren a la productividad por hora trabajada (Coremberg, 2009; Marshall, 2009). Considerando este aspecto, en este artículo se retoman ambas medidas, la productividad por trabajador y la evolución de las horas trabajadas. Asimismo, aun sin incrementar las horas trabajadas, el aumento de productividad puede conseguirse con un incremento en la intensidad del trabajo, eliminando tiempos muertos, comprometiendo un esfuerzo mayor por parte del trabajador, etc. Este factor solo puede ser captado en estudios que aborden procesos productivos específicos, y por tanto, en estudios de mayor alcance aparecerá entremezclado con las fuentes mencionadas antes. 
Ahora bien, tanto la tecnología, como la organización productiva y la forma de utilización del trabajo, tienen especificidades en función del tipo de producto y la intensidad en el uso de capital y de trabajo. En este sentido, si se compara la productividad en un momento del tiempo de dos establecimientos que producen bienes con procesos disímiles, no es posible afirmar que uno ha incorporado más tecnología o ha introducido mejoras organizativas respecto al otro, pues parte de esa diferencia está explicada por la propia naturaleza del proceso productivo. Por ejemplo, un establecimiento dedicado a la refinación de petróleo tendrá siempre una mayor productividad que otro en el cual se confecciona vestimenta, aun cuando este último haya incorporado la tecnología de punta para el sector textil. Así, las mediciones de productividad agregada - ya sea de diferentes establecimientos de una misma rama de actividad o del total de ramas de actividad de la economía - combinan características y tendencias de unidades heterogéneas.

La medida de productividad brinda buena información cuando se utiliza en la comparación internacional de establecimientos de un mismo sector — por ejemplo, la industria textil argentina en relación a la misma industria en otros países-, o cuando analizamos su variación en el tiempo, es decir, en términos relativos a las características propias de cada sector u actividad. Esta segunda opción es la que utiliza este trabajo dado que la comparación de niveles de productividad entre sectores es relevante para el análisis del límite superior, ya que justamente la intensidad en el uso del capital o el trabajo y el tipo de bien producido, inciden en este límite.

Coremberg (2009) ofrece una medición de la productividad laboral en Argentina en el marco de su propuesta de estimación de la contribución de los distintos factores productivos al crecimiento. Nos interesa destacar algunas de sus advertencias respecto a la medición de la productividad laboral. La primera refiere al numerador del indicador de productividad. Las distintas mediciones habitualmente utilizadas se basan en índices de volumen físico. Sin embargo, como estas mediciones no se realizan por producto específico sino para un sector o para el total de la economía, la necesidad de agregar bienes heterogéneos implica recurrir a la moneda para su homogeneización. Así, aunque la evolución del indicador resultante no se vea afectada por los precios, la medición inicial congela el efecto de los precios relativos de aquel momento para toda la serie (Coremberg, 2009).

La segunda advertencia refiere al denominador, en particular cuando se utiliza la cantidad de ocupados. Dicho autor señala que según la fuente utilizada puede haber un subregistro de la mano de obra: si utilizamos registros de la seguridad social, los trabajadores informales no aparecen (Coremberg, 2009). Por su parte, en las encuestas de hogares solo se relevan datos de la ocupación principal, invisibilizando así las ocupaciones de quienes tienen más de un empleo. 
Cuando analizamos sectores de actividad específicos, en particular la industria, cobra relevancia otra causa de subregistro. La proliferación de formas de contratación mediadas por empresas creadas para tal fin, ya sean agencias de empleo eventual o empresas subcontratadas, desdibuja las estadísticas de empleo sectorial, ya que trabajadores que desempeñan sus tareas en una cierta empresa industrial, son contratados por una empresa de servicios. Así, dependiendo de la fuente de información y de la forma en la cual es declarado el empleo, puede ser considerado un ocupado de un sector u otro (Marshall, 1998). Dado que aquí se utiliza el Censo Nacional Económico (CNE), este problema no se presenta en tanto "para facilitar la realización de estudios de productividad y evitar el sesgo que ocasionarían los cambios en la relación laboral (entre asalariados, no asalariados, contratados y personal de agencia), en el CNE 2004/05 se relevó información sobre la cantidad de personal de agencia y que cobra por factura." (INDEC, 2005: p. 12).

Un factor explicativo que se debe tener en cuenta en el análisis de la evolución de la variable es el cambio en la composición de la rama. En particular, resultan relevantes: $i$ ) el cambio en la composición por tamaño de establecimiento, y ii) el cambio en la composición sectorial. Por ejemplo, diversos autores postulan que el incremento de productividad que se dio en Argentina durante la década de 1990, es atribuible al cambio en el patrón industrial y al cierre de establecimientos pequeńos y el consecuente aumento de la concentración (Katz \& Stumpo, 2001; Schvartzer, 1997). Asimismo, el crecimiento de la demanda de los bienes producidos puede motorizar incrementos de productividad. Sin embargo, es preciso distinguir dos mecanismos: el primero es que, habiendo capacidad instalada ociosa, un incremento en la demanda motiva un aumento en la utilización, lo cual acrecienta la producción a un ritmo mayor que la contratación de nuevos trabajadores; el segundo consiste en ofrecer las condiciones de rentabilidad para que haya incorporación de nuevas tecnologías.

Más allá de la distancia entre aquello que se quiere medir y lo que efectivamente se mide, nos interesa aquí destacar la relación entre la productividad y el empleo. Siendo este último el denominador del indicador de productividad, la misma va a aumentar siempre que el producto crezca más que el empleo. De allí su carácter procíclico: en contextos de crecimiento de la actividad, es posible aumentar la producción sin incrementar el plantel inmediatamente; mientras que en contextos de recesión, se reduce la producción antes de que se despidan o suspendan trabajadores. ${ }^{3}$ Así, un incremento de productividad no necesariamente es una buena noticia: puede deberse a un magro crecimiento

3 Las medidas tendientes a flexibilizar el uso de la fuerza de trabajo apuntan a alinear mejor la cantidad de trabajadores al ritmo de actividad, de manera tal de atenuar la caída de productividad que se espera al reducir el nivel de actividad. 
del producto con nulo, o incluso negativo, crecimiento del empleo — tal como ocurrió en Argentina en los últimos años de los noventa-; y si no es compensada por aumentos equivalentes en el nivel de salarios traerá consigo un empeoramiento de la distribución funcional del empleo. Vale aclarar que en el periodo estudiado en este trabajo ha habido una expansión del empleo en todas las ramas, por lo cual, los incrementos de productividad no se deben a reducciones de los planteles.

A partir de los datos provenientes del CNE y de la Encuesta Industrial Mensual (EIM) del Instituto Nacional de Estadísticas y Censos (INDEC) analizaremos la relación entre la evolución de la productividad y del salario en Argentina durante el periodo 2003-2012. Para analizar la evolución de ambas variables es suficiente evaluar el índice de salarios y de productividad de la EIM. Sin embargo, proceder de tal forma implicaría predicar sobre los cambios en la brecha entre el límite superior y el salario respecto a 2003. Ese ejercicio es válido y es de interés para este trabajo, pero oculta aquella brecha inicial de 2003. Por ese motivo, incorporamos los niveles de ambas variables: pues es el nivel de productividad lo que actúa como un límite real. Así, una tasa de variación del salario por encima de la productividad no implica que el límite superior haya sido desbordado, sino que la brecha se ha reducido respecto a 2003. Los niveles de productividad y salarios surgen del Censo Económico, y las variaciones anuales de la EIM, que con base en tal censo, provee un seguimiento de las principales variables de la industria.

Los censos económicos se realizan en Argentina cada diez años y constituyen la fuente de información sobre la estructura productiva con mayor alcance geográfico y de actividades. Los datos utilizados aquí corresponden al CNE 2004 que relevó información referida a 2003. A partir de los datos recolectados en cada establecimiento, se dispone de datos de valor de la producción, puestos ocupados —asalariados y no asalariados- y masa salarial. Con estas variables construimos los indicadores de productividad y salario promedio de cada sector de la industria manufacturera para el año 2003. ${ }^{4}$ Para analizar la tendencia a lo largo del periodo 2003-2011, estos datos fueron actualizados con información proveniente de la EIM.

El relevamiento de la EIM abarca tres mil locales industriales de distinto tamaño, que cuentan con más de diez personas ocupadas, ${ }^{5}$ dispersos en diferen-

4 Se analizan los sectores industriales a dos dígitos según CLANAE CNE04, que con esa desagregación es equivalente al CAEs-Mercosur utilizado en la EIM. Se excluyeron dos sectores, ya que debido a su baja participación en el empleo no estaban disponibles todos los indicadores necesarios para este trabajo. Estos dos sectores son: Fabricación de maquinarias de oficina, contabilidad e informática y Reciclamiento.

5 El CNE, en cambio, comprende unidades productivas de distinto tamaño. Para compatibilizar los datos de ambas fuentes, solo se utilizó la información del censo correspondiente a los establecimientos de más de diez ocupados. 
tes puntos del país. En esta encuesta se considera como obrero al personal con categoría no superior a la de supervisor y que está afectado al proceso productivo (elaboración de bienes, control de calidad, acarreo dentro del local, tareas auxiliares en la producción, mantenimiento de equipo de producción, almacenaje y reparación). El índice de productividad surge del cociente entre el índice de volumen físico y el índice de obreros ocupados. Debido a que también se encuentra disponible el índice de horas trabajadas, se calcularon las medidas de productividad por ocupado y por hora y las consideraciones relevantes que surgen de su comparación se mencionan a lo largo del artículo. Por su parte, el índice de salario por obrero (ISO) publicado por el INDEC, expresa la evolución del salario correspondiente a ese personal y comprende el salario bruto por todo concepto (horas normales y extras, vacaciones, licencias por enfermedad, premios y bonificaciones, excepto aguinaldo, indemnizaciones por despido y asignaciones familiares). El índice de salario real utilizado en este artículo, se construye a partir del cociente del Iso y el índice de precios al consumidor ${ }^{6}$ (IPC).

\section{El desenvolvimiento macroeconómico en la Argentina actual}

La Argentina culminó la década del noventa inmersa en una profunda crisis social, política y económica que tuvo su momento cúlmine en los años 20012002. La salida de esa crisis implicó la devaluación del peso argentino luego de sostener durante diez años la paridad 1-a-1 con el dólar estadounidense. En efecto, la resolución de la crisis posibilitó renovadas condiciones de acumulación de capital. Por un lado, la pesificación asimétrica posdevaluación que estableció distintos tipos de cambio para deudores y acreedores permitió la licuación de las deudas de las grandes empresas y el saneamiento de sus balances. Por otro, debido a la inflación generada por la misma devaluación, hubo una fuerte caída del costo laboral real llevándolo a niveles mínimos históricos. La devaluación nominal de 2002, que finaliza ubicándose en torno al 400\%, permitió la reducción de los costos de producción en dólares y permitió mejorar la competitividad tanto de los sectores exportadores como de aquellos que compiten internamente con importaciones, ofreciendo un considerable margen de protección cambiaria.

6 El IPC es publicado también por el INDEC. Sin embargo, debido a la intervención de este instituto en 2007 y las sospechas en torno a la manipulación del IPC, para el periodo 2007-2012 se utiliza aquí un IPC construido por el Centro de Estudios para el Desarrollo Argentino (CENDA) y el Centro de Investigación y Formación de la República Argentina (CIFRA) a partir de los datos provenientes de las Direcciones de Estadística de siete y nueve provincias, respectivamente. Mayores precisiones metodológicas pueden encontrarse en CIFRA (2012). 
Asimismo, creció la demanda internacional de los commodities que vende Argentina, tanto por el aumento en las cantidades comerciadas como por el incremento de precios. ${ }^{7}$ De esta forma, los sectores exportadores vinculados a la explotación de bienes naturales se vieron beneficiados por términos de intercambio muy favorables, lo cual redundó en un avance de la frontera de producción sojera y un incremento en el número de proyectos vinculados a la minería.

Sin embargo, en lo que respecta a la dinámica sectorial y su vínculo con la inserción internacional (participación de las ventas que se destinan al mercado externo), los cambios macroeconómicos no parecen haber incidido. El perfil exportador heredado de la década de los noventa no se modifica durante la recuperación económica posterior: en 2008, el 85\% de las ventas externas son explicadas por la industria alimenticia, el sector automotor, refinación de petróleo, elaboración de productos y sustancias químicas, y manufactura de metales comunes (siderurgia y aluminio primario). Estos mismos cinco sectores explicaban el 78\% de las ventas entre los años 1993 y 2001. Asimismo, vale destacar que dicha preeminencia se asienta en características comunes de las actividades económicas en cuestión: estructuras de oferta concentradas alrededor de un reducido número de grandes empresas extranjeras; poca demanda de fuerza de trabajo; salarios bajos en dólares; ciclos económicos, en materias de precios, dependientes del mercado mundial, y escasas articulaciones internas en el plano productivo, entre otras (Azpiazu \& Schorr, 2010).

Más allá de las particularidades sectoriales, en una economía integrada al mercado mundial con baja productividad relativa, un tipo de cambio alto supone la caída del precio relativo de los bienes no transables, en particular de uno de los principales precios de la economía: el salario (Féliz \& Perez, 2007). En efecto, entre 2001 y 2002 el salario real tuvo la caída más pronunciada desde fines de los ochenta (Graña \& Kennedy, 2008). Debido a la brecha entre precios mayoristas y minoristas, la caída del costo laboral fue aún más pronunciada, permitiendo cierta recomposición salarial sin afectar las ganancias de las empresas. El patrón distributivo de principios de la década intentó consolidarse a través de un pacto social, pero a partir de 2007, en un contexto de crecimiento de los precios al consumidor, los reclamos por recomposiciones salariales comenzaron a agudizarse.

Durante esos años el contexto institucional presentó numerosas modificaciones. En los primeros años el gobierno tuvo un rol activo en la promoción de aumentos salariales en el sector privado mediante incrementos de suma fija no remunerativa, lo que fue complementado con aumentos incorporados a los

7 Esto se debe, por un lado al aumento de la demanda por el ingreso de China como gran comprador, y por otro, a la presión que la demanda especulativa de commodities ejerció sobre el precio de las mismas. 
salarios básicos por decreto. ${ }^{8}$ Dada esta modalidad de regulación, hacia 2005 el sector privado registrado había logrado recomponer el salario real al nivel de 2001, aunque sin alcanzar el nivel medio de la década previa.

A partir de 2004 se modifica el marco legal de la negociación colectiva al derogarse la Ley de Reforma Laboral (No 25.250), sancionada en el 2000.9 Dicha reforma refuerza los convenios sectoriales al incluir cláusulas inmodificables por la negociación de empresa, y restituye la ultraactividad de los convenios —esta figura, abolida con la reforma laboral de 2000, significa que un convenio es válido hasta que se negocie un nuevo acuerdo, incluso aunque se haya vencido su periodo formal- Esto permitió reactivar la negociación colectiva, y desde 2006 se consolidan las rondas de negociación donde los grandes gremios acuerdan y actualizan las pautas salariales del convenio sectorial (Etchemendy, 2011). Luego, las diferencias en el poder de negociación de los distintos sindicatos y cámaras empresariales se tradujeron en aumentos dispares según el sector (CENDA, 2009).

Estas formas de intervención, regulando los salarios básicos o promoviendo paritarias, afectan directamente a los trabajadores registrados, pero no a los no registrados. El mercado de trabajo argentino ha heredado de la década de los noventa, y aún mantiene, elevados niveles de empleo no registrado que implica que, hacia el cuarto trimestre de 2012, el 34.6\% de los asalariados se encuentren en esta condición. Una de las principales medidas para recomponer el salario de este grupo desfavorecido fue el aumento del salario mínimo vital y móvil (sмVM), que arrastra indirectamente sus salarios. Sin embargo, a pesar del impulso del crecimiento económico con un nuevo patrón de creación de empleo, ${ }^{10}$ los trabajadores informales recién en 2011 lograron recuperar su salario real a niveles — ya bajos_ de 2001. Por su parte, los trabajadores del

8 En efecto, la mayor intervención estatal no se circunscribió solo a este ámbito, sino que es uno de los rasgos característicos del nuevo modo de regulación, interviniendo activamente en la formación de precios (a través de impuestos al comercio exterior, acuerdos de precios internos, fijación de tarifas, etcétera).

9 La cual flexibilizaba el empleo en varios sentidos, pero aquí rescatamos en particular sus implicancias sobre la negociación. En primer lugar, obstruía la negociación por actividad al exigir nuevos requisitos y establecer que, en caso de concurrencia de convenios de diferente ámbito, sería aplicable el del ámbito menor (aunque tuviera peores condiciones). En segundo lugar, habilitaba el "descuelgue" del convenio colectivo por acuerdo entre empleador y sindicato y derogaba la regla de ultraactividad de los convenios colectivos tanto para los vigentes como para los futuros (Recalde, 2011).

10 Groisman (2011) seńala que en el quinquenio 2004-2009 prevalece la creación de puestos de trabajo asalariados registrados en la seguridad social. Entre puntas, este tipo de empleo creció un 44\%, mientras que los puestos no registrados lo hicieron solo en 7\%. Además se regularizaron las contrataciones del sector público, aunque parte de la caída del empleo no registrado en este sector se debe a la reducción del peso de los planes de empleo, que al no tener descuento jubilatorio se computan como no registrados (CENDA, 2007a). 
sector público, cuyos gremios sí cuentan con negociaciones salariales, en 2012 aún no recuperaban el nivel de $2001 .^{11}$

$\mathrm{Al}$ observar la variación trimestral desestacionalizada del producto, se pueden distinguir dos periodos: la etapa 2003-2007 de crecimiento sostenido a "tasas chinas", y la que se abre a partir de 2008, con un desenvolvimiento del producto interno bruto (РIB) más moderado y la novedad de tasas de variación negativas. Así es que, para el primer periodo, se observó una tasa de crecimiento trimestral promedio de 2.28\%, mientras que en 2008-2012 la misma cae a $1.23 \%$.

Las diferencias mencionadas entre periodo y periodo también tienen su correlato en el mercado de trabajo. Entre los años 2003 y 2007 se aprecian francas caídas en las tasas de desocupación y subocupación (mayores al 10 y $8 \%$, respectivamente). ${ }^{12}$ Sin embargo, desde 2008 en adelante, las series se estabilizan $^{13}$ (gráfico 1).

\section{Gráfico 1. Crecimiento económico (variación trimestral y promedio del PBI) y tasa de desocupación y subocupación. Periodo 2003-2012}

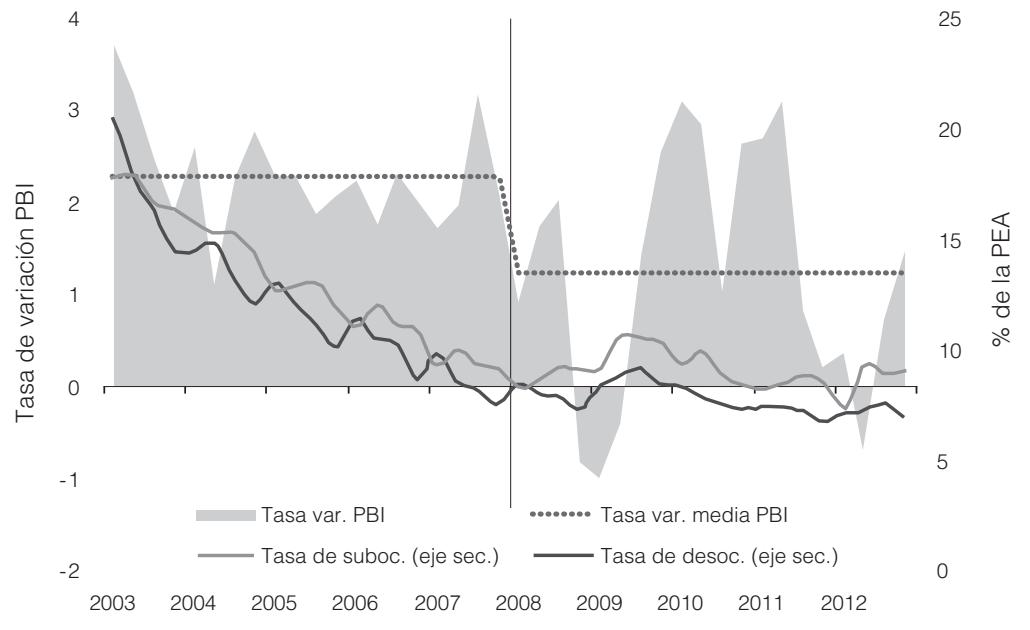

Fuente: Elaboración propia con datos del INDEC (2015).

11 Tomando los índices de salarios publicados por INDEC y el IPC-INDEC, el sector informal habría superado el nivel de 2001 en marzo de 2008, y el sector público en agosto del mismo ańo. Utilizando estimaciones alternativas para el índice de precios en ninguno de los dos sectores se ha logrado superar ese nivel.

12 En particular, en el periodo bajo análisis, se observa una dinámica "en espejo" entre la tendencia de la tasa de variación del PBI (construida a partir de una media móvil de dos periodos), y la tasa de desocupación (Barrera, 2009).

13 El desvío estándar de las series de desocupación y subocupación en el segundo periodo fue de 0.6 y 0.8 , mucho menores a las existentes en la etapa inicial ( 3.0 y 2.9 , respectivamente). 
En términos de salarios, también hay importantes diferencias entre ambos periodos. El cuadro 1 expone algunas variables seleccionadas que dan cuenta de ello. En la primera etapa es notable el incremento del smvm por encima del salario medio, lo que evidencia el rol que tuvo esta política para impulsar los salarios más bajos. Lo contrario ocurre con los salarios promedios, que presentan un crecimiento nominal mayor en el segundo subperiodo. A su vez, al interior del conjunto de asalariados, el aumento del salario de trabajadores registrados es superior a la media del conjunto de asalariados, esto es, incluyendo a los no registrados. En las tres variables salariales contempladas, el aumento nominal es superior a la inflación del periodo.

Cuadro 1. Variación de los salarios reales y negociación colectiva en Argentina 20032012. Variables seleccionadas

\begin{tabular}{llllll}
\hline $\begin{array}{l}\text { Variación } \\
\text { punta-a-punta }\end{array}$ & SVMV real & $\begin{array}{l}\text { Salario real neto pro- } \\
\text { medio sector privado } \\
\text { registrado }\end{array}$ & $\begin{array}{l}\text { Salario real promedio } \\
\text { total asalariados }\end{array}$ & Ritmo negocial & Cobertura negocial \\
\hline $2003-2007$ & $340 \%$ & $164 \%$ & $61 \%$ & $195 \%^{*}$ & $222 \%^{*}$ \\
$2008-2012$ & $56 \%$ & $236 \%$ & $65 \%$ & $42 \%$ & $5.63 \%$ \\
\hline
\end{tabular}

(*) Los datos correspondientes a ritmo y cobertura de la negociación pertenecen a la primera etapa del periodo 2004-2007. Fuente: Elaboración propia con datos del Ministerio de Trabajo, Empleo y Seguridad (MTEySS) (2015), Social Sistema Integrado Provisional Argentino (SIPA) (2015), INDEC (2015) y CENDA (2011).

Estas diferencias entre el comportamiento del svmv, que expresa una forma particular de intervención del Estado, y los salarios promedios, que resultan de la conjunción de otras formas de intervención estatales, pero también sindicales y empresariales, dan cuenta de distintos patrones en la regulación salarial. En efecto, a lo largo del primer subperiodo hubo un marcado aumento del ritmo negocial, esto es, de la cantidad de acuerdos y convenios firmados, y de la cantidad de trabajadores alcanzados por los mismos. Tal incremento sentó las bases para que en el quinquenio siguiente los incrementos salariales se acuerden en tales instancias. Si bien la tasa de crecimiento de acuerdos y de la cobertura negocial se redujo, siguió siendo positiva, lo que aumentó el alcance de esta instancia de regulación salarial.

En lo que a productividad se refiere, para dichas subetapas Marshall \& Perelman (2013) señalan diferencias en elasticidad empleo-producto y en la fuente del crecimiento de la productividad entre estos dos subperiodos. Entre 2004 y 2007 el país experimentó una alta elasticidad empleo-producto y el crecimiento de la productividad se consiguió mediante la ampliación de la escala de producción utilizando capacidad instalada. En cambio, entre 2008 y 2011 la elasticidad fue moderada y el crecimiento de la productividad habría sido dinamizado por cambios tecnológicos y organizacionales. 
En el segundo subperiodo la desaceleración de la actividad y de la absorción de mano de obra fue más pronunciada en el sector productor de bienes, que era el que más había crecido a inicios de la década. Es decir: los sectores que más se recuperaron entre 2003 y 2007 fueron los que más se desaceleraron en la segunda etapa (CENDA, 2009). Así, desde 2008 el desempeño del empleo en el sector privado fue menos dinámico que el empleo total, pues decrece la incidencia del sector industrial como creador de empleo y crece la participación del sector público ${ }^{14}$ — que de ese modo tiene un rol contracíclico conteniendo la caída del empleo- - La recuperación del salario en el sector privado registrado fue más pronunciada en el primer quinquenio. En efecto, durante ese periodo los conflictos laborales en ese sector fueron escasos, mientras que sí ocurrían en el público, que no lograba una recuperación del salario a niveles de 2001.

La recuperación de la cantidad de puestos en la industria acumulada a lo largo de la década no fue suficiente para retornar a los niveles de mediados de la década de los noventa. En efecto, la participación de la industria en el producto se recupera en la primera mitad de la década — aunque aun así no vuelve al nivel de 1997, correspondiente al auge del ciclo económico anterior-, mientras que la participación en el empleo asalariado registrado es siempre decreciente —excepto en el periodo 2003-2004.

De aquí surgen dos consideraciones importantes. Por un lado, de la evolución de la participación industrial en el empleo se desprende que el sector terciario ha ganado peso en la estructura ocupacional. Por el otro, la conjunción de ambas participaciones indica que el producto medio (producto/total de ocupados) de la industria ha crecido en relación al resto de la economía.

El gráfico 2 muestra la participación de los distintos sectores industriales en el empleo industrial registrado al inicio y al final del periodo en análisis. Alimentos y bebidas es el sector que presenta una porción mayoritaria de los puestos de trabajo industriales y que más empleos ha generado durante la posconvertibilidad. Sin embargo, desde 2004 la tasa de variación de empleo del sector ha sido menor al nivel general de la industria, por lo cual ha perdido algunos puntos en su participación relativa. Los demás sectores tienen una participación menor al 10\%, evidenciando por un lado, la importancia del sector de alimentos y bebidas y, por otro, el bajo grado de concentración sectorial del $70 \%$ del empleo restante.

14 Una importante porción del aporte de la administración pública a la creación de empleo registrado está vinculado, en realidad, con el registro de personal previamente ocupado en el sector (CENDA, 2011). A pesar de los pases a planta se ha incrementado la participación de contratos por locación de servicios en la órbita del Estado. Otra parte del incremento se debe a la absorción de empresas privatizadas en los noventa (CENDA, 2007b). 
Gráfico 2. Participación en el empleo registrado y el producto industrial.

Años 2003 y 2012.

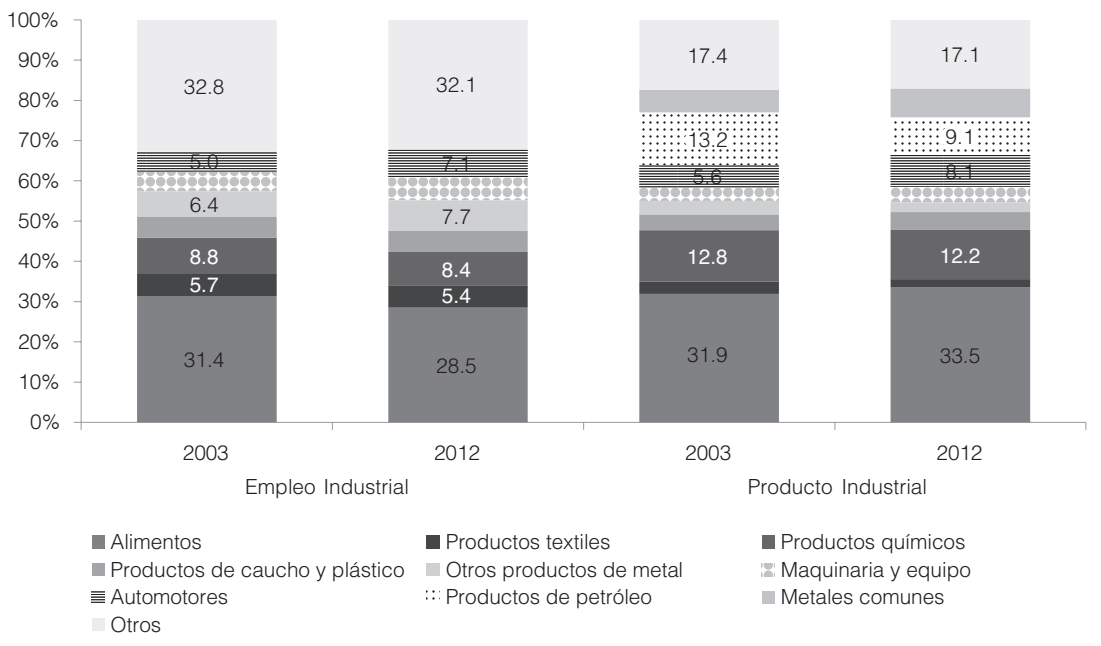

Fuente: Elaboración propia con base en MTySS (2015).

En la siguiente sección analizamos la evolución de los salarios de los trabajadores asalariados registrados en la industria manufacturera en relación a la productividad. Hemos visto aquí que los trabajadores registrados del sector privado han tenido una evolución mucho más favorables de los salarios que otros conjuntos de trabajadores. Este aspecto debe ser considerado para matizar los resultados presentados en la próxima sección, pues las conclusiones que se obtienen no pueden extenderse a toda la estructura ocupacional. En particular, se analiza, por un lado, un conjunto de los trabajadores del sector privado: los ocupados en la industria manufacturera y, por otro, la estructura productiva industrial. La evolución de la desigualdad, tanto salarial como productiva, contemplando solo este sector, subestima seguramente la desigualdad general. Sin embargo, consideramos que este recorte es pertinente y nos aporta elementos importantes: más allá del peso del sector industrial en la estructura del empleo y del producto, es relevante conceptual y simbólicamente.

\section{La relación entre productividad y salarios al interior de la industria}

La evolución de la relación del salario con la productividad, según nuestro marco teórico, explica el desplazamiento del límite superior. En esta sección nos concentramos en este punto, no sin antes discutir el nivel en el que se encuentran 
las variables al inicio del periodo estudiado. Luego evaluamos si la dinámica de dicha relación ha conllevado una profundización de las heterogeneidades sectoriales o de homogeneización de las condiciones salariales.

Nivel y evolución de la productividad y los salarios sectoriales

El año 2003, punto de partida de nuestro análisis, es un momento en el cual la brecha entre productividad y salario real en Argentina se había ampliado sustancialmente como consecuencia de la inflación cambiaria de 2002-2003. En el gráfico 3 se presentan los índices de productividad y salario real de la industria manufacturera, y se puede apreciar cómo la fuerte caída del salario en 2002 amplía la brecha respecto de la productividad.

Gráfico 3. Índice de productividad y de salario real por obrero entre 1997 y 2012. Nivel general de la industria manufacturera

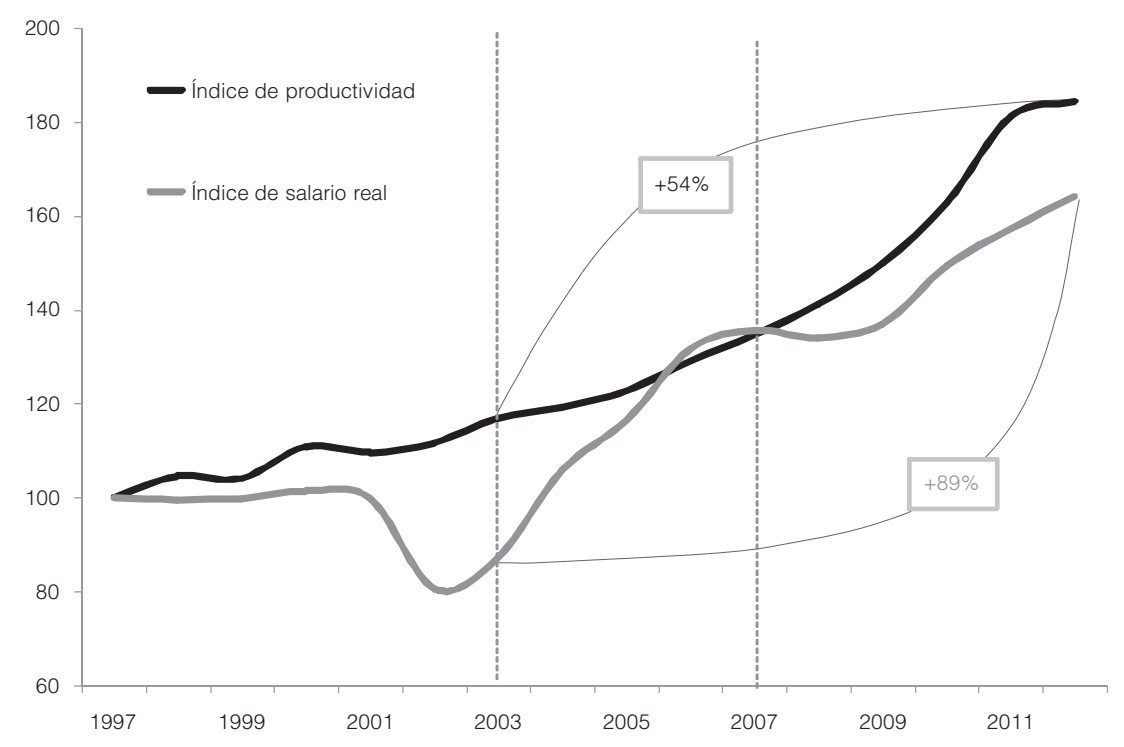

Fuente: Elaboración propia con base en datos de INDEC (2015) y CENDA (2011).

Entre 2003 y 2012, la productividad en la industria aumentó 54\%, mientras que los salarios reales de los obreros industriales crecieron en un porcentaje mayor: 89\% — sin embargo, ese incremento no alcanzó para mantener la misma relación que en 1997 - Ahora bien, estos incrementos punta-a-punta 
se han concentrado en diferentes subperiodos, que se corresponden con los ya identificados en el apartado anterior de este artículo.

Entre 2003-2007, el crecimiento del salario real fue muy superior al de la productividad ( 56 y 15\%, respectivamente), en gran medida debido a que la recomposición de salario nominal que se da en el periodo no es contrarrestada con incrementos de precios. Durante el quinquenio siguiente (2008-2012), en cambio, los salarios reales crecieron $23 \%$ mientras que la productividad lo hizo en $28 \%$. Si bien ya en 2008 había una dinámica negocial intensa, los incrementos de salario nominal fueron siendo erosionados por la inflación. A su vez, la producción continuó creciendo y disminuyó la incorporación de nuevos trabajadores. ${ }^{15}$

A nivel agregado y para ambos subperiodos, el aumento de productividad se explica por otro en la producción mayor al que se dio en la cantidad de ocupados. Al comparar las series de productividad por ocupado y por hora se evidencia que la intensidad horaria no tiene un rol relevante en esta dinámica; por ende, podemos concluir que el aumento de productividad no se debió a la extensión de la jornada sino a la intensidad del trabajo (mejoras tecnológicas, cambios organizativos, mejor utilización de la capacidad instalada, etcétera).

Esta dinámica a nivel agregado surge de comportamientos heterogéneos de los distintos sectores industriales. En el cuadro 2 se clasifican los sectores industriales según su nivel de salarios y productividad en 2003. Los de altos (bajos) salarios son aquellos cuyo nivel de salarios está por encima (por debajo) del salario medio industrial; aquellos con alta (baja) productividad tienen un nivel de productividad mayor (menor) a la media industrial.

Cuadro 2. Nivel de productividad y salarios en 2003

\begin{tabular}{|c|c|c|}
\hline & Altos salarios & Bajos salarios \\
\hline Alta productividad & $\begin{array}{l}\text { Productos de tabaco. Papel y productos de pa- } \\
\text { pel. Fabricación de coque. Sustancias y pro- } \\
\text { ductos químicos. Metales comunes. Aparatos } \\
\text { de radio y televisión. Vehículos automotores. } \\
\mathbf{( 2 3 . 2 \% )}\end{array}$ & $\begin{array}{l}\text { Alimentos y bebidas. } \\
(\mathbf{3 0} \%)\end{array}$ \\
\hline $\begin{array}{l}\text { Baja producti- } \\
\text { vidad }\end{array}$ & $\begin{array}{l}\text { Edición e impresión. } \\
\mathbf{( 4 . 3 \% )}\end{array}$ & $\begin{array}{l}\text { Productos textiles. Confección de prendas de } \\
\text { vestir. Curtido y terminación de cueros. Produc- } \\
\text { ción de madera. Productos de caucho y plás- } \\
\text { tico. Productos minerales no metálicos. Metal } \\
\text { excepto maquinaria. Maquinaria y equipo NCP. } \\
\text { Maquinaria y aparatos eléctricos. Instrumentos } \\
\text { médicos y de precisión. Equipos de transporte } \\
\text { NCP. Muebles y colchones y otras industrias. } \\
\mathbf{( 4 2 . 3 \% )}\end{array}$ \\
\hline
\end{tabular}

Nota: El porcentaje indicado en negrita entre paréntesis indica la participación de los sectores de cada celda en el empleo total industrial.

Fuente: Elaboración propia con base en CNE 04/05

15 En 2009 y 2010, en efecto, cayó el empleo industrial como producto de la crisis internacional. 
Del cuadro 2 se desprenden dos aspectos relevantes para este estudio. Primero, en general se corrobora que los sectores que tienen productividad por debajo (por arriba) de la media, son los que ofrecen salarios más bajos (más altos) que el salario medio. Segundo, una de las excepciones es el sector más relevante en términos de participación en el empleo y en el producto industrial: alimentos y bebidas.

$\mathrm{Al}$ analizar la evolución de la productividad y el salario por sector encontramos una nueva diferencia entre subperiodos. Los gráficos 4 y 5 muestran la variación punta-a-punta de la productividad y el salario en 2003-2007 y 2008-2012, respectivamente. En el gráfico 4 vemos que el incremento salarial por encima del incremento de productividad es común a casi todos los sectores industriales. En cambio, en el siguiente subperiodo (gráfico 5) el nivel general ya comentado esconde comportamientos sectoriales más heterogéneos: en diez sectores la productividad creció por encima del salario, y en otros once sucedió lo contrario.

Gráfico 4. Variación de la productividad y del salario real por obrero y por sector entre 2003 y 2007

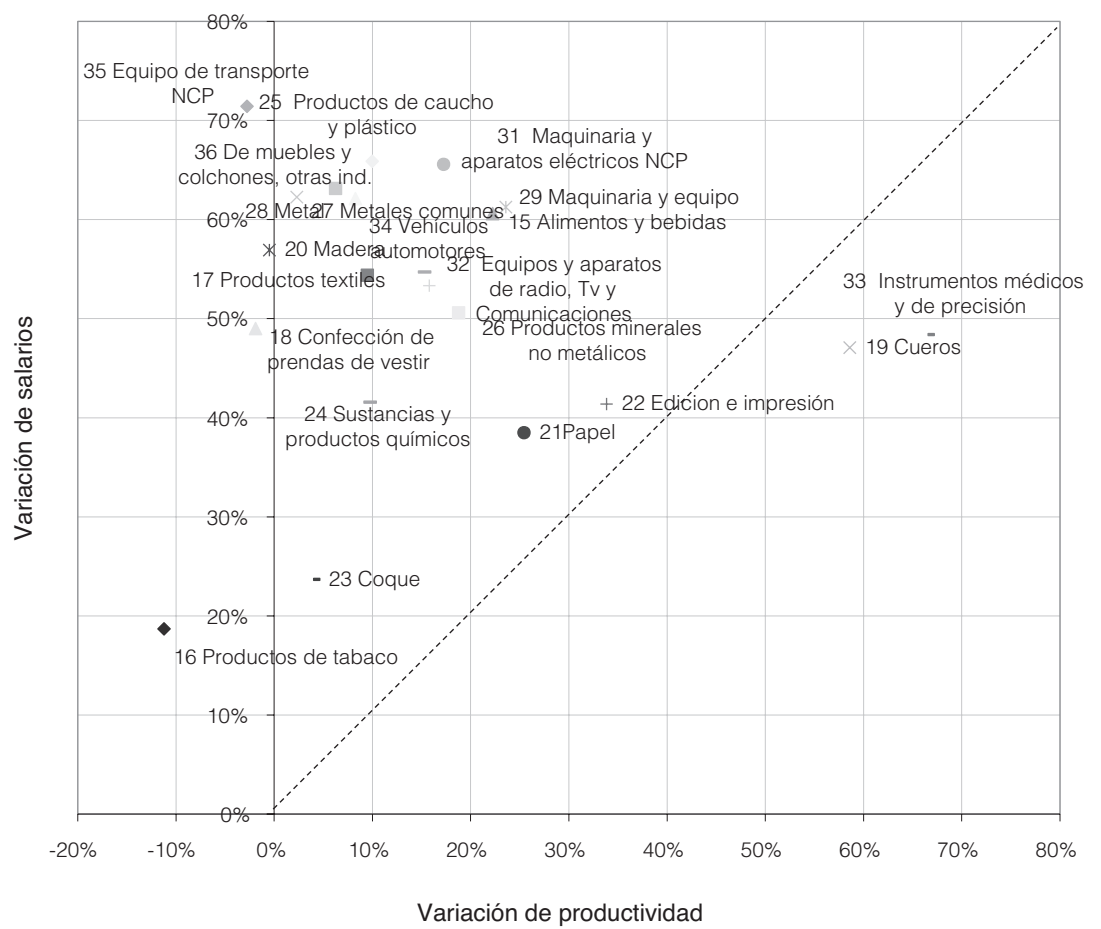

Fuente: Elaboración propia con base en INDEC (2015) y CENDA (2011). 
Gráfico 5. Variación de la productividad y del salario real por obrero y por sector entre 2008 y $2012^{*}$

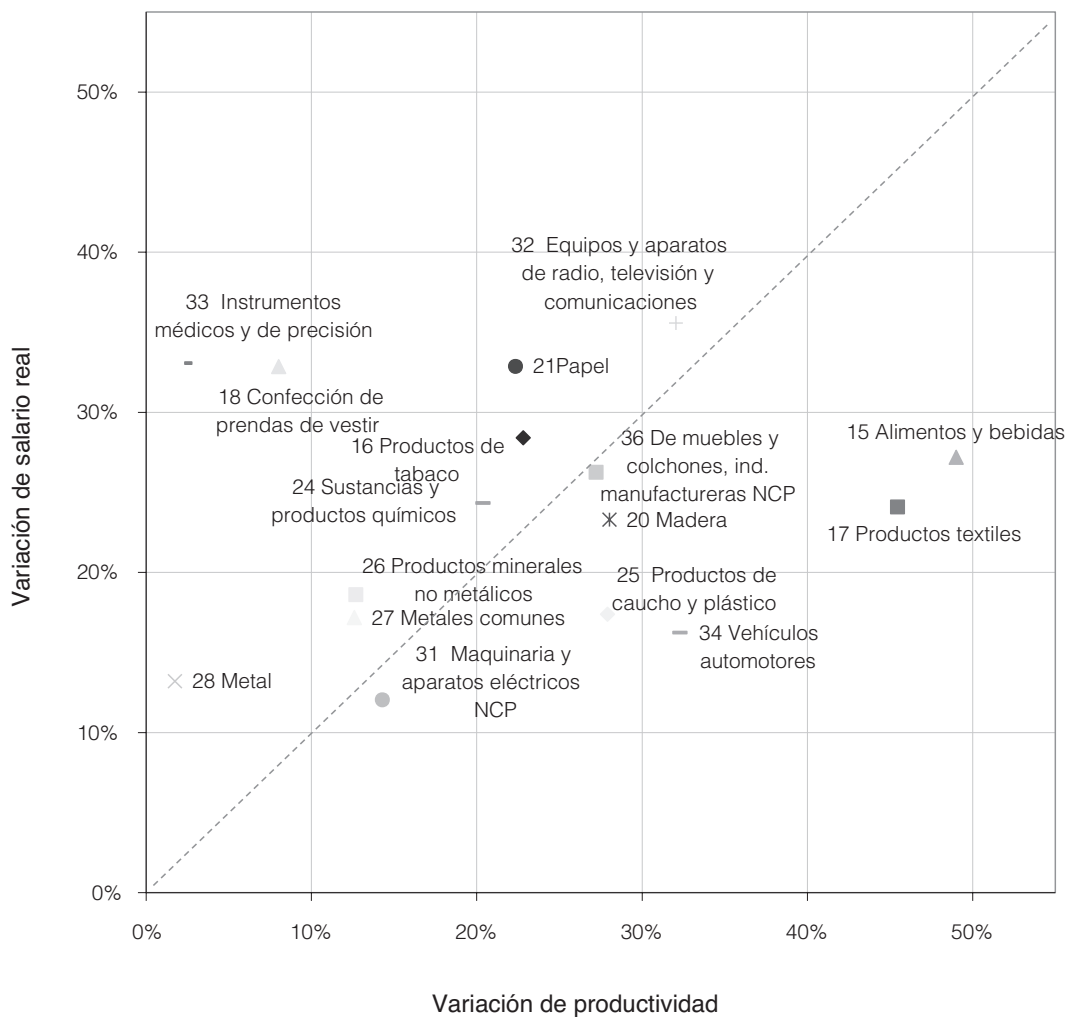

\begin{abstract}
* Las siguientes ramas tuvieron una variación negativa de la productividad, con variaciones positivas del salario, y por ende no aparecen en el cuadrante que se presenta aquí — entre paréntesis se indica la variación de productividad y de salarios correspondiente-: Edición e impresión (-15\%, 17\%); Coque (-22\%, 28\%); Maquinaria y equipo NCP (-8\%, 26\%); Equipo de transporte $(-37 \%, 21 \%)$. Estas cuatro ramas corresponden la situación del cuadrante superior, donde el aumento de salarios fue mayor al de productividad. En cambio, la productividad del sector Cueros aumentó $71 \%$, con $23 \%$ de aumento del salario real y fue excluida para mantener la escala del gráfico.
\end{abstract}

Fuente: Elaboración propia con base en INDEC (2015) y CENDA (2011).

Del gráfico 4 se desprende que en 2003-2007 hay un acercamiento acentuado y generalizado del salario al límite superior determinado por la productividad. En el quinquenio siguiente, en cambio, solo en algunos sectores el salario crece por encima de la productividad, acortando la brecha entre ambos. Por tanto, en el primer subperiodo, la recuperación del salario en forma generalizada sugiere que la reducción de la brecha con la productividad no se explica por el accionar de cada colectivo de trabajadores. Es relevante considerar aquí el rol que el Estado asume en esos ańos, decretando los aumentos generalizados 
de suma fija —al menos para los trabajadores registrados de la industria, cuyos salarios analizamos aquí.

En efecto, ambos subperiodos muestran particularidades en lo referido al rol del Estado en la negociación salarial. Mientras que en los primeros años el Estado interviene impulsando incrementos salariales y la reapertura de la negociación, en el segundo subperiodo, su rol apunta a la alineación de pautas salariales. En ambos casos, su forma de intervención responde a una problemática macroeconómica específica: en los primeros años de la posconvertibilidad era necesario un aumento salarial generalizado que reactivara el componente de consumo de la demanda agregada; en los últimos años, la aceleración de la inflación motiva la intervención — directa o indirecta — en la negociación para moderar los aumentos y evitar el aceleramiento también de los incrementos salariales.

\section{Desigualdad salarial y productiva, ¿parte de un mismo fenómeno?}

En la presente sección presentamos evidencia, resumida en el índice de Theil, sobre la estructura y dinámica de las disparidades en productividad y salarios al interior de la industria. Si el valor medio de productividad o salarios del sector $x$ se acerca (se aleja) al promedio de la industria, entonces se produce una caída (un incremento) en la desigualdad sectorial. Asimismo, si cae (aumenta) la participación del producto - o empleo- sectorial de un sector $x$ con valor medio alejado del promedio industrial, la desigualdad desciende (crece). ${ }^{16}$

En lo que se refiere a la productividad, el comportamiento de las series muestra una tendencia decreciente de la desigualdad. El índice que capta la disparidad total en la productividad media sectorial indica que esta prácticamente se reduce a la mitad entre los años 2003 y 2012 (gráfico 6). Este resultado puede ser explicado ya sea porque se ha reducido la brecha entre las productividades de distintas ramas, o bien porque han ganado peso las ramas con productividad media en detrimento de aquellas con muy alta o muy baja productividad. Para diferenciar estas dos explicaciones utilizamos el índice de Theil fijo. ${ }^{17}$

16 Para conocer las ventajas y desventajas de este indicador de desigualdad, véase Barrera (2009).

17 El ejercicio consiste en mantener fijo, a lo largo de toda la serie, la ponderación inicial de cada sector. En un caso, lo que se refiere a la participación del producto sectorial en el producto total (Prod fix), y en otro, fijar la distribución de productividades iniciales (Ptv fix). 


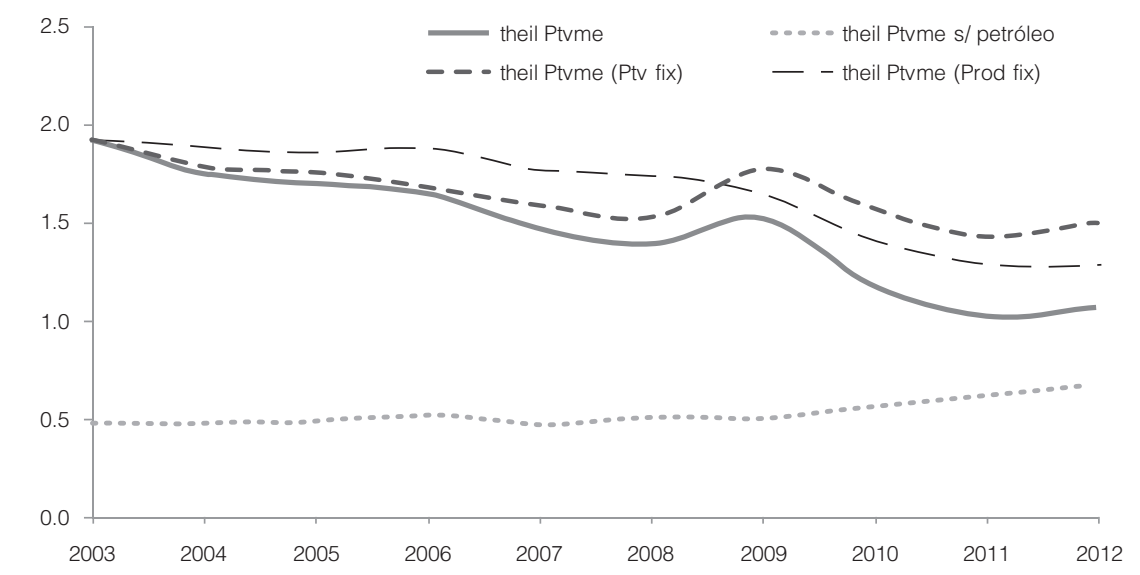

Fuente: Elaboración propia con base en datos de CNEO4 y EMI (2015).

En primer lugar, al fijar las participaciones sectoriales (Prod fix) se puede observar que, en buena medida, la tendencia decreciente es explicada por la reducción en la disparidad de productividades relativas. En particular, la reducción se da por un achicamiento de la brecha del sector más productivo: "Fabricación de coque, productos de la refinación del petróleo". En el año 2003, este sector era más de ocho veces más productivo que el promedio, mientras que en 2012, su productividad se había recortado a 5.5 veces.

En segundo lugar, luego de fijar las productividades relativas (Ptv fix), se observa que los cambios en las contribuciones al producto industrial también coadyuvaron a la reducción de la desigualdad. $\mathrm{Al}$ inicio del periodo, tres sectores explican prácticamente el $60 \%$ del producto industrial: alimentos y bebidas $(33 \%)$, sustancias y productos químicos (14\%), y petróleo (12\%). Estos sectores, con productividades iguales o por encima del promedio, retroceden en su participación hasta rozar el $50 \%$ en o 2008. Luego, el incremento en la disparidad que se observa en la curva para los años 2008 y 2009, se debe a una recuperación en las participaciones sectoriales, presumiblemente por el impacto diferencial de la crisis internacional en nuestro país, sobre estos y el grupo restante de ramas industriales.

En tercer lugar, dado que en gran medida los cambios en el índice de Theil son explicados fundamentalmente por el sector petróleo - tanto en lo que se refiere a disparidad en productividad como en participación en el producto-—, se vuelve necesario excluir el sector del análisis para observar lo que sucede en el resto de la industria en el periodo. Así, al excluir el sector más productivo, encon- 
tramos una primera gran diferencia: se observa una caída en el nivel de desigualdad del orden de las tres cuartas partes (véase theil Ptvme s/petróleo del gráfico 6). En segundo lugar, encontramos que la caída en la heterogeneidad estructural ${ }^{18}$ que se apreciaba en la totalidad de los sectores estudiados, ya no se repite. Por el contrario, a partir de 2009, el crecimiento de la productividad y participación del sector de producción de alimentos y bebidas — que como mencionamos, explica una tercera parte del producto industrial y posee una productividad media un $40 \%$ más alta que la del total de las ramas- genera incrementos globales de desigualdad.

En lo que respecta a los salarios, en el gráfico 7 puede observarse que la desigualdad cae entre los años 2003 y 2005, momento a partir del cual, más allá del incremento coyuntural por la crisis, los valores del índice de Theil permanecen al nivel de aquel año. Para comprender este resultado examinamos por separado los cambios en los salarios relativos entre ramas de actividad y en el peso relativo de cada sector en el empleo industrial total.

Gráfico 7. Desigualdad salarial entre ramas industriales. Índice de Theil. Años 2003-2012

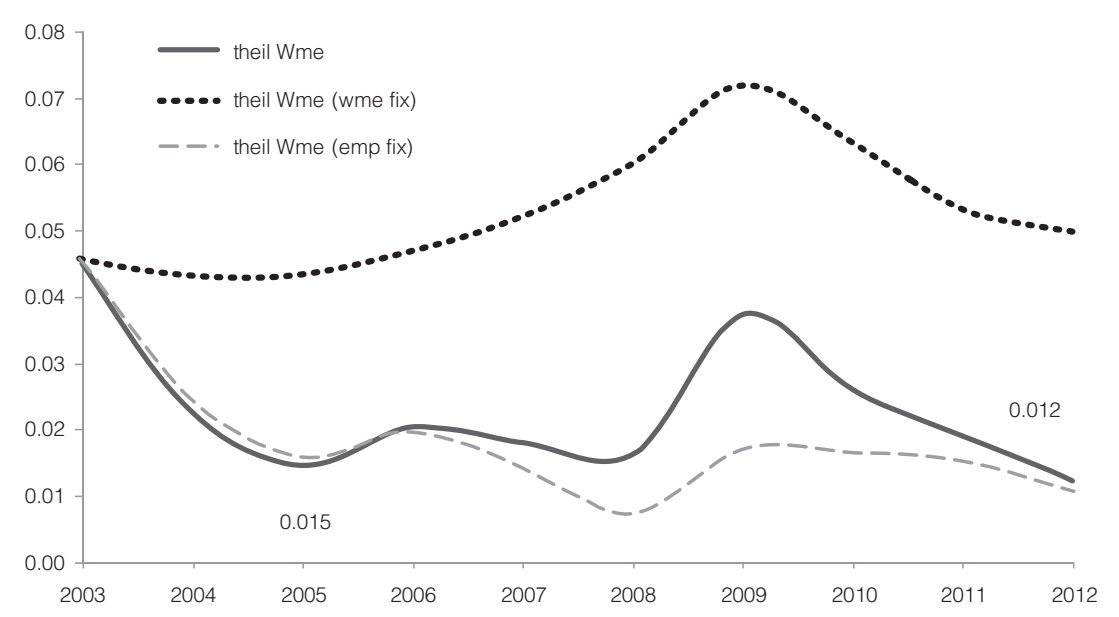

Fuente: Elaboración propia con base en datos de CNE04 y EMI, 2015.

18 El término "heterogeneidad estructural" se utiliza para describir un rasgo particular de las economías subdesarrolladas. Mientras las economías desarrolladas muestran niveles similares de productividad en los distintos sectores de actividad, en las estructuras productivas subdesarrolladas hay brechas amplias entre los mismos. Si bien en las primeras también hay ciertas diferencias de productividad, la clave es que en las segundas la discontinuidad es notable — no es gradual — y comprende sectores significativos y no pequeñas fracciones de producto y empleo (Pinto, 1970; Prebisch \& Cabańas, 1949). 
Al fijar las participaciones de empleo sectorial (emp fix), se observa que la reducción en la desigualdad salarial se relaciona con los cambios en los salarios relativos, especialmente entre 2003 y 2008. La dinámica de los salarios acompańa la mejora en los indicadores del mercado de trabajo: durante el primer subperiodo los salarios recuperan, parcialmente, el poder de consumo, al tiempo que caen las tasas de desocupación y subocupación. La segunda etapa exhibe una notable estabilidad, lo cual estaría indicando un congelamiento de las retribuciones relativas entre sectores de actividad. Inclusive aquella estructura de salarios relativos pareciera consolidarse antes: en 2005, cuando el índice toma un valor de 0.015, y mantenerse prácticamente inalterada hasta $2012(0.012)$. Cabe señalar que si bien el salario medio del sector petrolero incide en mayor proporción que el del resto de los sectores por encontrarse 3.3 veces por encima del promedio industrial, el resto de los salarios medios acompañan la tendencia a la reducción de las desigualdades.

A partir de 2006 la reducción de la desigualdad vía reacomodamiento de salarios relativos, se ve contrarrestada parcialmente por un incremento generado por cambios en la composición del empleo (véase wme fix). El incremento de la desigualdad a partir de 2007 y en particular el pico de desigualdad durante la crisis de 2009 se explican principalmente por el crecimiento relativo del empleo en el sector químico y petrolero, ambos con salarios por encima de la media industrial. Si bien el sector de petróleo representa solo el 1\% del empleo total, la sensibilidad del índice a los cambios de empleo del sector, sigue siendo elevada dada las diferencias en salarios mencionadas. ${ }^{19}$

De 2009 en adelante la composición del empleo explica la reducción de la desigualdad. Sin embargo, tal reducción se debe fundamentalmente a la de la participación de sectores con mayores salarios relativos como vehículos automotores y metales comunes, así como también a una leve caída de la participación del sector químicos y petróleo.

A modo de síntesis, resaltamos que la caída en la desigualdad salarial se concentró en la primera etapa. El motivo no fue un cambio en la composición del empleo por sector, sino que efectivamente hubo una reducción en la desigualdad entre los salarios medios de cada sector. A su vez, a lo largo del periodo se redujo también la desigualdad en productividad. Esto implicaría que los límites superiores que enfrentan los trabajadores de distintas ramas de actividad se han ido alineando. Sin embargo, este resultado ya no se mantiene si se excluye del análisis el sector petrolero; por lo que solo podemos concluir que se han

19 Recordemos que aunque la estructura salarial se encuentre congelada al inicio del periodo, los aportes a la desigualdad producto de los cambios en la composición del empleo siguen siendo ponderados por la estructura salarial. 
achicado las brechas de productividad con ese sector, pero no entre el resto de los sectores industriales.

\section{Reflexiones finales}

Los enfoques convencionales sobre determinación salarial no suelen contemplar las condiciones de valorización del capital. En cambio, nuestra propuesta asume que, en este marco de relaciones sociales, el salario se define entre dos límites: uno superior, dado por la tasa de ganancia y uno inferior, bajo el cual ya no podría garantizarse la reproducción de la vida. En este artículo nos hemos centrado en el primer aspecto, reconociendo, no obstante, la necesidad de avanzar en un abordaje que integre ambos campos. Por otra parte, dado que la dinámica de la tasa de ganancia puede ser explicada a través del ritmo de variación de la productividad y los precios, en este trabajo hemos adoptado dicho criterio para estudiar el límite superior. Durante los años 2003-2012, en Argentina se produce una fuerte recuperación del empleo y la actividad, con un rol activo del Estado en materia de regulación salarial (incrementos de salario por decreto, reactivación de la negociación colectiva y el salario mínimo). El crecimiento de los salarios de los obreros industriales registrados fue superior al de la productividad. Esto no implica haber erosionado la tasa de ganancia, sino simplemente recuperar parte del terreno perdido como consecuencia de la crisis de 2001-2002, cuando la brecha entre productividad y salarios se había ampliado sustancialmente.

A nivel de sectores se observa una fuerte correspondencia entre productividad y salarios en el nivel del año 2003, tanto en aquellos que se encuentran por encima como por debajo del promedio de cada variable. Luego, la dinámica de ambas series muestra dos subperiodos bien diferenciados: mientras que en 2003 y 2007 los salarios reales crecen por encima de la productividad de manera generalizada, a partir de 2008, junto con la aceleración de precios, deviene una etapa de dispersión en el comportamiento de dichas variables, que en términos agregados se manifiesta en crecimiento diferencial a favor de la productividad.

En términos de desigualdad, los resultados indican que hubo una reducción que no tiene correlato en desigualdad productiva. Inclusive en el periodo 2008 2012, con desigualdad salarial estable, la desigualdad productiva aumenta. A modo de hipótesis, podemos afirmar que en esta etapa el comportamiento de la desigualdad salarial está explicado fuertemente por la política de regulación salarial del Estado. En el primer subperiodo, la reducción coincide con incrementos salariales de suma fija y reactivación de la negociación colectiva; mientras que en el segundo, en un contexto de aceleración de la inflación y una negociación 
colectiva dominante, la pauta de inflación actúa como una referencia que alinea los acuerdos salariales y cristaliza una estructura de salarios industriales, sin grandes cambios relativos (Marshall, 2013). En nuestro marco de análisis, este resultado implica que se mantienen las brechas en los límites superiores que enfrentan trabajadores ocupados en distintas ramas de la industria.

Los resultados de este trabajo abren nuevas preguntas para continuar la investigación. Por un lado, nos planteamos cuán pertinente es la medida de productividad como aproximación a ese límite superior de los salarios, pero también qué implicaría esto para sectores distintos a la industria manufacturera en los cuales la idea de productividad se hace más difusa o es inapropiada. Por otro lado, es necesario incorporar a esta mirada un análisis de los factores que explican la distancia entre ese límite superior fijado por la dinámica de acumulación y el salario efectivo: la organización de los trabajadores, las respuestas empresariales y las formas de regulación estatal.

Más allá de estas preguntas y de los elementos que aún quedan por desarrollar, consideramos que este marco de análisis permite conciliar cierto determinismo del cual solemos pecar quienes consideramos que la estructura productiva y las condiciones de acumulación tienen un rol excluyente para comprender el nivel y las características del empleo con la certeza de que es posible disputar, aun en este marco de relaciones sociales, la forma en la que se distribuye el producto social.

\section{Referencias}

Azpiazu, D. \& Schorr, M. (2010). La industria argentina en la posconvertibilidad: reactivación y legados del neoliberalismo. Problemas del Desarrollo, 41(161), 111-139.

Barrera, F. (2009). Desigualdad salarial: una aproximación a sus determinantes macroeconómicas en la Argentina de la post-convertibilidad. Ponencia presenta en $9^{\circ}$ Congreso Nacional de Estudios del Trabajo "El trabajo como cuestión central” (ASET). Buenos Aires, Argentina.

Beccaria, L. \& Yoguel, G. (1988, enero-marzo). Apuntes sobre la evolución del empleo industrial en el periodo 1973-1984. Desarrollo Económico. Revista de Ciencias Sociales, 27(108) 589-605.

Botwinick, H. (1993). Persistent Inequalities: Wage Disparity under Capitalist Competition. Princeton: Princeton University Press.

Carciofi, R. (1986). Salarios y política económica. Buenos Aires: CEPAL. 
Centro de Estudios para el desarrollo Argentino (CENDA). (2011). El trabajo en Argentina. Condiciones y Perspectivas. Informe trimestral, 20.

Centro de Estudios para el desarrollo Argentino (CENDA). (2009). El trabajo en Argentina. Condiciones y Perspectivas. Informe trimestral, 16.

Centro de Estudios para el desarrollo Argentino (CENDA). (2007a). El trabajo en Argentina. Condiciones y Perspectivas. Informe trimestral, 13.

Centro de Estudios para el desarrollo Argentino (CENDA). (2007b). El trabajo en Argentina. Condiciones y Perspectivas. Informe trimestral, 11.

Centro de Investigación y Formación de la República Argentina (CIFrA). (2012). Propuesta de un indicador alternativo de inflación. Recuperado de http://www.centrocifra.org.ar/publicacion .php?pid=55

Coremberg, A. (2009). Midiendo las fuentes del crecimiento en una economía inestable: Argentina. Productividad y factores productivos por sector de actividad económica y por tipo de activo. Estudios y Perspectivas. Buenos Aires: CEPAL.

Etchemendy, S. (2011). El diálogo social y las relaciones laborales en Argentina 2003-2010: Estado, sindicatos y empresarios en perspectiva comparada. Buenos Aires: огт.

Féliz, M. \& Pérez, P. (2007). ¿'Tiempos de cambio? Contradicciones y conflictos en la política económica de la posconvertibilidad. En Boyer, R. \& Neffa, J. (Eds.). Salida de crisis y estrategias alternativas de desarrollo (pp. 319-350). Buenos Aires: Miño y Dávila Editores.

Graña, J. M. \& Kennedy, D. (2008). Salario real, costo laboral y productividad. Argentina 19472006. Análisis de la información y metodología de estimación. Documento de Trabajo, (12).

Groisman, F. (2011). Argentina: los hogares y los cambios en el mercado laboral (2004-2009). Revista CEPAL, (104), 81-102.

Indec. (2005). Censo Nacional Económico 2004/2005. Sintesis Metodológica. Buenos Aires: Instituto Nacional de Estadística y Censos. Recuperado de www.indec.gov.ar/economico2005/ definitivos/CNE04_metodologia_040810.pdf

Infante, R. (2011). América Latina en el «umbral del desarrollo». Un ejercicio de convergencia productiva. Documento de Trabajo, (14).

Katz, J. \& Stumpo, G. (2001). Regímenes sectoriales, productividad y competitividad internacional. Revista CEPAL, (75), 137-159. 
López-Calva, L. F. \& Lustig, N. (2010). Declining Inequality in Latin America: A Decade of Progress? Washington, D. C.: Brookings Institution Press.

Marshall, A. \& Perelman, L. (2013). El empleo industrial: balance de una década (2003-2012). Ponencia presentada en el $11^{\circ}$ Congreso Nacional de Estudios del Trabajo, "El mundo del trabajo en discusión. Avances y temas pendientes” (ASET). Buenos Aires, Argentina.

Marshall, A. (2013). Wage-setting Regimes and Inequality: Evidence from Argentina. Presentado en Regulating for Equitable and Job-Rich Growth, Conference of the Regulating for Decent Work Network (RDW). Ginebra.

Marshall, A. (2009). Desempeño y perfil del empleo en la industria argentina (2003-2008). Investigación presentada en X Jornadas Argentinas de Estudios de Población (AEPA). San Fernando del Valle de Catamarca, Argentina.

Marshall, A. (1998). Empleo en la Argentina, 1991-1997: nuevas pautas de comportamiento después de la liberalización económica? Equipo Técnico Multidisciplinario para Argentina, Brasil, Chile, Paraguay y Uruguay. Recuperado de http://www.sidalc.net/cgi-bin/wxis.exe/?IsisScript= FCEAL $\cdot x i$ \& method $=$ post $\&$ formato $=2 \&$ cantidad $=1 \&$ expresion $=m f n=007845$

Marshall, A. (1979, octubre-diciembre). Notas sobre la determinación del salario. Desarrollo Económico. Revista de Ciencias Sociales, 19(75), 377-392.

Marx, K. (2004). El capital, Tomo I (Vol. 1). Buenos Aires: Siglo XXI Editores Argentina.

Mincer, J. (1974). Schooling, Experience, and Earnings. Nueva York: Columbia University Press, for NBER.

Pérez, P. \& Barrera, F. (2012). Estructura de clases, inserción laboral y desigualdad en la postconvertibilidad. En Féliz, M. et al. (Ed.). Más allá del individuo: clases sociales, transformaciones económicas y politicas estatales en la Argentina contemporánea (pp. 223-247). Buenos Aires: Editorial El Colectivo.

Pinto, A. (1970, enero-marzo). Naturaleza e implicaciones de la "heterogeneidad estructural" de la América Latina. El Trimestre Económico, 37(145-1), 83-100.

Prebisch, R. \& Cabañas, G. M. (1949). El desarrollo económico de la América Latina y algunos de sus principales problemas. El Trimestre Económico, 16(63-3), 347-431.

Recalde, H. P. (2011). Reformas laborales durante la convertibilidad y la posconvertibilidad. Voces en el Fénix, (6), 6-11. 
Schvartzer, J. (1997). La estructura productiva argentina a mediados de la década del noventa. Tendencias visibles y un diagnóstico con interrogantes. Buenos Aires: Centro de Estudios Económicos de la Empresa y Desarrollo/FCE/UBA.

Shaikh, A. (1980). Marxian Competition versus Perfect Competition: Further Comments on the So-called Choice of Technique. Cambridge Journal of Economics, (4), 75-83.

Solow, R. M. (1956). A Contribution to the Theory of Economic Growth. The Quarterly Journal of Economics, 70(1), 65-94. doi: http://doi.org/10.2307/1884513

Watson, I. (2002). Wage Inequality and Underemployment: Australia in the 1990s. Journal of Industrial Relations, 44(1), 88-107.

Recibido el 10 de mayo de 2015. Aceptado el 13 de febrero de 2017. 